Review

\title{
The role of FGF21 in type 1 diabetes and its complications
}

\author{
Jian Zhang ${ }^{1,2}$, Wenya Weng 3 , Kai Wang ${ }^{2,4}$, Xuemian Lu ${ }^{3}$, Lu Cai ${ }^{2,5 凶}$, Jian Sun ${ }^{1 凶}$ \\ 1. The Center of Cardiovascular Disorders, the First Hospital of Jilin University, Changchun, China. \\ 2. Pediatrics Research Institute, Department of Pediatrics, University of Louisville, Louisville, Kentucky, USA. \\ 3. The Third Affiliated Hospital of Wenzhou Medical University, Ruian Center of Chinese-American Research Institute for Diabetic Complications, Ruian, \\ China. \\ 4. The First Affiliated Hospital of Wenzhou Medical University, Wenzhou, China. \\ 5. Department of Pharmacology and Toxicology, University of Louisville, Louisville, Kentucky, USA
}

$\square$ Corresponding authors: Dr. Jian Sun, Department of Cardiology, the First Hospital of Jilin University, Changchun, China. E-mail: sunjianemail@126.com; Dr. Lu Cai, Pediatric Research Institute, University of Louisville, 570 S. Preston Street, Baxter I, Suite 304F, Louisville, KY 40202, USA. E-mail: 10cai001@louisville.edu

(c) Ivyspring International Publisher. This is an open access article distributed under the terms of the Creative Commons Attribution (CC BY-NC) license (https:// creativecommons.org/licenses/by-nc/4.0/). See http://ivyspring.com/terms for full terms and conditions.

Received: 2018.01.18; Accepted: 2018.04.21; Published: 2018.06 .02

\begin{abstract}
Data from the International Diabetes Federation show that 347 million people worldwide have diabetes, and the incidence is still rising. Although the treatment of diabetes has been advanced, the current therapeutic options and outcomes, e.g. complications, are yet far from ideal. Therefore, an urgent need exists for the development of more effective therapies. Numerous studies have been conducted to establish and confirm whether FGF21 exerts beneficial effects on obesity and diabetes along with its complications. However, most of the studies associated with FGF21 were conducted in the patients with type 2 diabetes. Subsequently, the effect of FGF21 in the prevention or treatment of type 1 diabetes and its complications were also increasingly reported. In this review, we summarize the findings available on the function of FGF21 and the status of FGF2l's treatment for type 1 diabetes. Based on the available information, we found that FGF21 exerts a hypoglycemic effect, restores the function of brown fat, and inhibits various complications in type 1 diabetes patients. Although these features are predominantly similar to those observed in the studies that showed the beneficial impact of FGF2 1 on type 2 diabetes and its complications, there are also certain distinct features and findings that may be of provide important and instructive for us to understand mechanistic insights and further promote the prevention and treatment of type 1 diabetes.
\end{abstract}

Key words: FGF21, Type 1 diabetes, Diabetic complications

\section{Introduction}

\section{Research status of the impact of FGF21 on type 1 diabetes}

Two major types of diabetes exist: type 1 diabetes (T1D) and type 2 diabetes (T2D). T1D is characterized by selective autoimmune destruction of islet $\beta$ cells [1]. Insulin analogues are commonly used for the treatment of T1D. However, sometimes, insulin therapy have suboptimal effects on glycemic control, many side effects can be observed $[2,3]$. In recent decades, a large number of studies have demonstrated that fibroblast growth factor 21 (FGF21) has multiple beneficial effects on obesity, T2D, and its complications [4-6]. Both acute [7] and chronic [8] administration of FGF21 can improve the metabolic status of T2D patients. Further examinations showed that FGF21 exerts not only important biological but also hypoglycemic effects in T2D patients [2]. Furthermore, it restored the function of brown adipose tissue [9], and inhibited various complication injuries [10-12]. Therefore, in T1D FGF21 may also play similar roles to those in T2D and whether it can be a novel approach for the treatment of T1D need urgently address.

\section{FGF2 1 structure and function}

FGF family consists of 22 structurally similar members, which, based on sequence homology and 
phylogeny, can be divided into seven subfamilies. The members of the FGF19 subfamily, including FGF15 / 19, FGF21, and FGF23, have important endocrine functions in the regulation of the metabolism of carbohydrates, lipids, phosphates, and vitamin D [13]. Most FGFs require heparin for stably binding to FGF receptors (FGFRs), which acts in an autocrine or paracrine manner and is not released into the circulation [14]. The endocrine FGF19 subfamily protein, which lacks the heparin-binding domain, exhibits a lower heparin-binding capacity that allows it to penetrate the cell membrane and enter to circulation $[15,16]$. The FGF21 signal transduction needs to bind to the FGF receptor and co-receptor. In FGF21 and FGF19, the protein $\beta$-Klotho act as a co-receptor, whereas klotho performs the function of co-receptor in FGF23 [17, 18].

Four FGFRs (FGFR1-FGFR4) have been identified so far, which have different FGF-binding specificities [19]. For example, FGF21 functions mainly through FGFR1 [20, 21], but FGFR and $\beta$-Klotho are two key components that are also required for FGF21 signaling [22]. It is based on the homology modeling that FGF21 folds into a $\beta$-trefoil-like core region with disordered N-terminus and C-terminus. FGF21 interacts with FGFRs at its $\mathrm{N}$-terminus and binds to $\beta$-Klotho at its C-terminus [23].

It was reported that not matter specific knockdown of $\beta$-klotho gene in adipocytes or global deletion of $\beta$-klotho gene would result in lost of FGF21-induced signaling tissue-specifically or systemically [24-26]. These findings demonstrate that $\beta$-Klotho is indeed a receptor that mediates the in vivo effects of FGF21. FGFR1 is widely expressed, but the expression of $\beta$-Klotho is limited by enrichment in white and brown adipose tissue, liver, pancreas, and central nervous system tissues [24, 27]. This phenomenon therefore explains why FGF21 exerts its biological effects in specific tissues or organs.

\section{Production of FGF2 1 and change of serum FGF2 1 contents in different subtypes of diabetes}

\section{FGF21 production in different organs}

Under normal conditions, FGF21 is produced in the liver, pancreas, and white and brown adipose tissues, whereas its expression and synthesis in other tissues and organs are lower [28]. Some studies found that FGF21 was produced in pancreatic $\beta$ cells, and even its expression levels there is higher than those in the liver, fat, and other tissues [28, 29]. Furthermore, FGF21 in pancreas can act in an autocrine manner to protect the quality and function of pancreatic $\beta$ cells
[30].

FGF21 may be released into the circulation but may also be locally involved through autocrine or paracrine mechanisms [30-32]. Importantly, in cases of physiological changes such as fasting, the liver is the only organ that releases FGF21 into the circulation [33]. Nevertheless, under mitochondrial stress conditions, muscles also release FGF21 into the circulation [34]. However, FGF21 is expressed at an exceedingly low level in muscles, which is abnormally significant only in muscle diseases [35].

\section{Changes in circulation levels of FGF21 in different subtypes of diabetes}

It is noteworthy that a higher blood FGF21 concentration was found in T2D and obese patients [36-38]. The abnormal rise in circulating FGF21 levels in T2D patients is considered to be a protective, compensatory response $[37,39]$.

The elevated levels of circulating FGF21 in diet-induced obesity, ob/ob, and $\mathrm{db} / \mathrm{db}$ mice may be associated with increased liver and adipose FGF21 mRNA expression [40-43]. In adults, FGF21 was found to be positively associated with obesity, fasting insulin, and triglycerides, and negatively with high density lipoprotein (HDL) [41]. Serum FGF21 is also elevated in obese children and is associated with free fatty acid (FFA) and leptin levels, whereas weight loss is accompanied by a decrease in FGF21 levels, indicating that obesity causes elevation in FGF21 concentration [44].

In another study, reduced plasma levels of FGF21 were established in streptozotocin (STZ)induced T1D mice [9]. Due to pancreatic damage and necrosis in T1D, the synthesis and secretion of FGF21 in this organ are substantially reduced [29]. On the other hand, a significant decrease in the body fat of T1D mice was observed as a result of gluconeogenesis disorders (Fig. 1F,G) [9]. Here, we use the data from the study by Kim et al. to show FGF21's hypoglycemic effect and restoration of brown adipose tissue function (Fig. 1). Therefore, it implies that the liver is the only major organ that produces circulating FGF21 in T1D, which may be partly responsible for the significant decrease of circulating FGF21 concentrations in the T1D.

\section{Pre- and postprandial differences of FGF21 levels in T1D and T2D}

Studies have demonstrated that the level of circulating FGF21 in normal mice increases during fasting [45]. In contrast, the FGF21 level in fasting STZ-induced mice is reduced, and their ability to increase circulating FGF21 is impaired (Fig. 1C) [9]. 
A

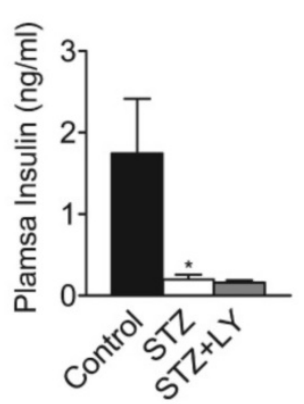

E

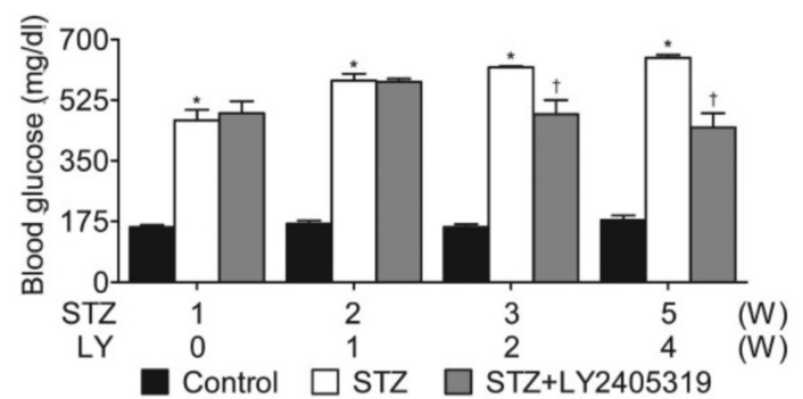

G

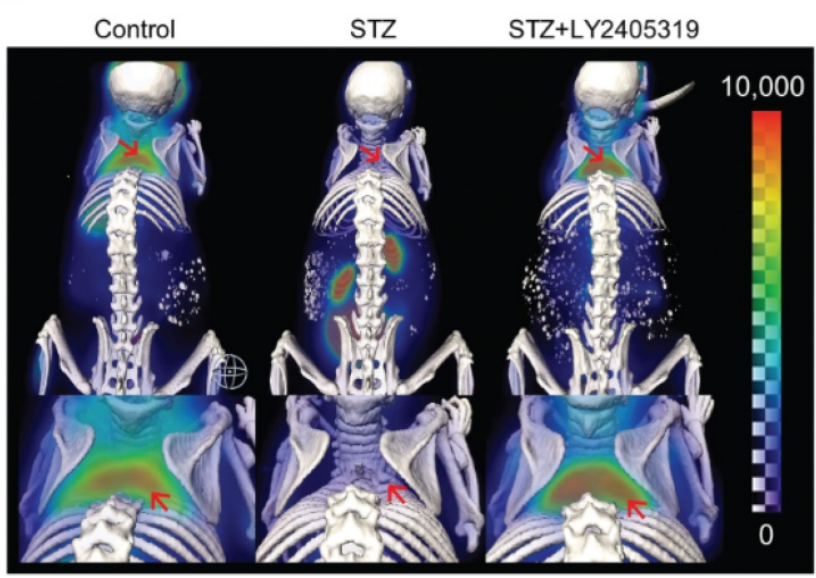

C

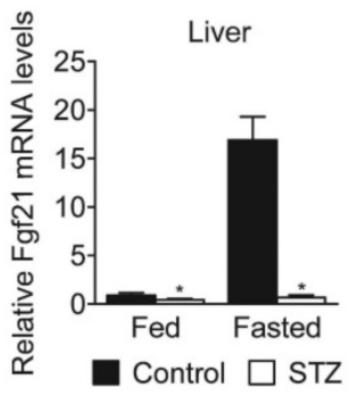

Control $\square$ STZ

(W)

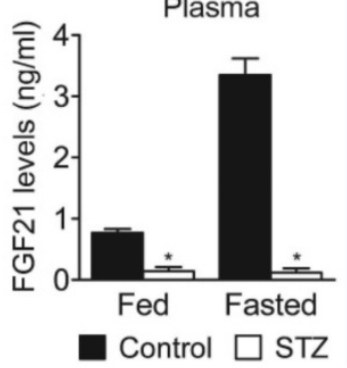

$\mathbf{F}$
D

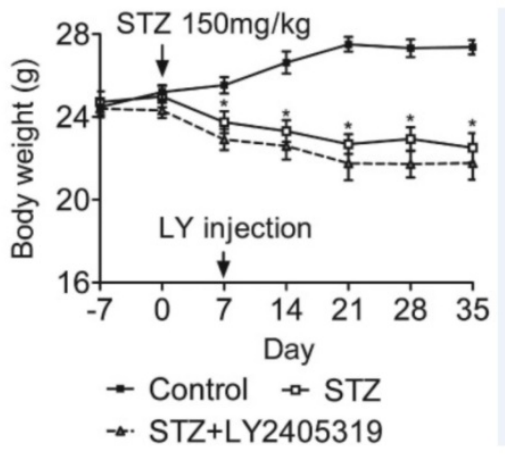

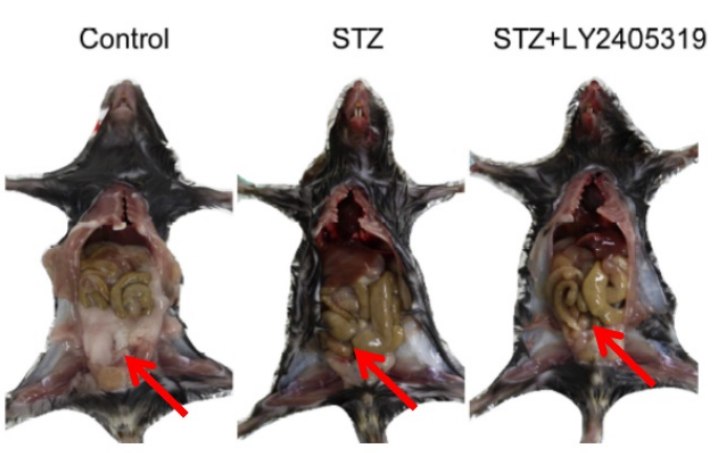

${ }^{18} \mathrm{~F}$-FDG uptake in BAT

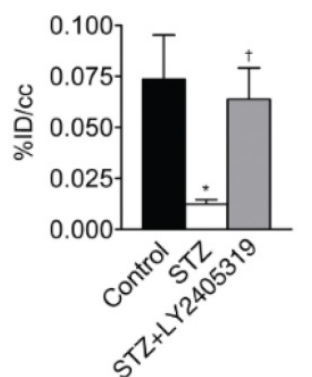

Figure 1.The hypoglycemic effect and restorative function of brown adipose tissues under TID conditions. The figure is a summary of the finding from the study by Kim et al. 9to confirm the hypoglycemic effect of FGF21 and also the restorative function of brown adipose tissue. A: FGF21 analogue (LY2405319, LY) did not increase insulin level that was significantly reduced in STZ-induced TID mice. B.C: FGF21 levels in the blood and liver were not increased in STZ-treated mice after meals. D: LY treatment did not affect the decreased body-weight by STZ-induced TID mice. E: LY treatment can significantly reduce blood glucose in STZ-induced TID mice. F,G: LY treatment did not restore WAT (F) but significantly restored BAT (G) in TID mice. The present figure is a combination of several parts of the original figures from the study by Kim et al.9 (here Figure A, B, C, D, and E form original Figure 1; Figure F form original Figure S1; Figure G form original Figure 2).

However, such pre- and postprandial changes in FGF21 levels were found similarly in diabetic mice and patients $[46,47]$. In one study, glucose tolerance tests were conducted in healthy people, patients with impaired glucose tolerance, and T2D patients. The results showed that in the first 60 minutes of the oral glucose tolerance test, the extent of the reduction in FGF21 in the patient groups was significantly lower than that in the healthy control group [46]. The fold changes in FGF21 concentrations were negatively correlated with insulin and C-peptide levels only in the healthy controls [46]. In T2D patients, the lack of a significant reduction in FGF21 levels in the first 60 minutes may be associated with impaired insulin secretion or impaired glucose tolerance [48]. Another investigation showed that the basal FGF21 levels in T1D patients were significantly lower than those in healthy controls [47]. After adjustments for age, gender, and body mass index (BMI), the healthy controls had a significant decrease in their postprandial FGF21 concentrations compared with that in T1D patients [47]. These results suggest that 
the physiological pattern of FGF21 secretion present in healthy individuals is lost in T1D patients. The concentration of FGF21 in T1D patients was not decreased after meals; the postprandial FGF21 concentration was equal to the baseline level [47].

Glucose is considered as one of the major factors affecting the secretion of FGF21 [49]. A study by Yang et al. showed that the elevation of insulin levels under normal conditions inhibited the production of FGF21 [50]. But Zibar et al. found no correlation between blood glucose and postprandial FGF21 when insulin treatment of T1D patients [47]. This result suggests that the reduction of circulating FGF21 in T1D patients is due to the abnormal capacity for FGF21 production [47].

Interestingly, earlier research established higher FGF21 concentrations in the female population, which was explained by the higher triglyceride levels detected [51]. Zibar et al. also found that the basic FGF21 concentration was significantly higher in T1D women than in men with this disease, but no gender difference was found in the healthy controls. Moreover, there was no difference in triglycerides between sexes. Hence, sex hormone differences can likely explain this phenomenon [47].

All above introduction and discussion reveal that FGF21 expression in the blood, liver, pancreas and adipose tissues are different between T1D and T2D and/or obesity conditions, which is summarized in the Table 1.

\section{Circulating FGF21 concentration is influenced by physiological factors}

Under normal conditions, circulating FGF21 is mainly produced in the liver [52], and its increased expression has been observed in obese mice [53] and humans [41], which may be the function of peroxisome proliferator-activated receptor a (PPARa). This increase in obesity seems to be associated also with the severity of nonalcoholic fatty liver disease [54,55], a compensatory increase in FGF21 in obesity similar to that detected insulin and leptin levels in T2D.
In addition to the changes in circulating FGF21 concentration in the pathological conditions of diabetes and obesity, FGF21 concentration is also affected by certain physiological factors [56]. According to the summary made by So et al. [56], the following physiological factors can be of major significance: (1) fasting; (2) diet; (3) cold exposure; and (4) exercise.

\section{Hypoglycemic effect of FGF21 in TID and its underlying mechanism}

FGF2 1 is involved in the protection of pancreatic $\beta$ cells

Wente et al. demonstrated that the continuous administration of FGF21 increased pancreatic $\beta$-cell activity by activating extracellular signal-regulated kinase 1/2 (ERK1/2) and protein kinase B (Akt) signaling, which increased serum insulin level, and protected pancreatic $\beta$ cells [30]. Uonaga et al. also showed that the administration of FGF21 in clinical islet transplantation protects pancreatic $\beta$ cells [57]. In addition, FGF21 was found to be expressed in pancreatic acinar cells, and its expression was significantly increased during cerulein-induced pancreatitis, but the elevation in FGF21 levels was transient [29]. After the acute phase of pancreatitis, with the continuous development of pancreatitis, the level of FGF21 in the pancreas is very low. Therefore, the temporary increase in the FGF21 level is a self-protective response [29].

FGF21 plays a role in reducing blood glucose level in T1D

Many experiments have confirmed that FGF21 controls blood glucose in both T1D and T2D mice [2, 9, 30]. In addition, FGF-21 did not cause hypoglycemia and cell proliferation [58, 59]. Precisely because FGF-21 plays an important role in the regulation of glucose and lipid metabolism, FGF21 is expected to be a good alternative to insulin in the treatment of diabetes $[59,60]$.

Table 1. Compare the FGF21 levels in different organs of TID and T2D/obesity.

\begin{tabular}{|c|c|c|c|c|c|c|}
\hline & \multicolumn{3}{|c|}{ T1D } & \multicolumn{3}{|c|}{ T2D/obesity } \\
\hline plasma & Mouse/human & $\begin{array}{l}\text { before and } \\
\text { after fasting } \\
\downarrow\end{array}$ & {$[9,46,47]$} & Mouse/human & $\begin{array}{l}\text { before fasting } \uparrow \\
\text { fasting } \uparrow \uparrow\end{array}$ & $\begin{array}{l}{[35-43,45-} \\
47,52,53]\end{array}$ \\
\hline liver & Mouse & $\downarrow$ & [9] & Mouse & $\uparrow$ & {$[39,40,42]$} \\
\hline $\begin{array}{l}\text { pancreas } \\
\text { adipose } \\
\text { tissue }\end{array}$ & Mouse & $\begin{array}{l}\text { acute injury } \uparrow \\
\text { late } \downarrow\end{array}$ & [28] & Mouse & $\begin{array}{l}\uparrow \\
\uparrow\end{array}$ & {$[39,40,42]$} \\
\hline
\end{tabular}


However, native FGF21 protein exhibits poor pharmacokinetic profiles; it has a short half-life range $[7,8,59]$ and is prone to proteolytic degradation in vitro or in vivo. Therefore, optimization of the FGF21 gene would enhance its biological activity. Studies have been performed on the site-specific pegylated FGF21 (PEG-FGF21) mutant aimed at prolongation of its in vivo half-life and reduction of its immunogenicity [61]. Reportedly, PEG-FGF21 had also a long-lasting effect of reducing blood glucose in T1D [62]. In the T1D model study by Xu et al., glargine was found to able to reduce blood glucose more rapidly, but the reduce blood glucose effect was prolonged after short-term PEG-FGF21 treatment [63]. Long-term treatment with PEG-FGF21 could keep blood glucose level near normal level [63].

One mechanism for FGF21 hypoglycemic effect may related to glucokinase (GK) and glucose transport (GLUT1). It is well-known that GK associates the glucose level with insulin secretion by converting glucose to glucose 6-phosphate, which is a rate-limiting step in glycolysis. In mouse models, the loss of heterozygosity for GK causes hyperglycemia, premature diabetes, and a decreased response to glucose stimulation [64]. Glucose 6-phosphatase (G6Pase) and phosphoenolpyruvate carboxykinase (PEPCK) are rate-limiting enzymes in gluconeogenesis [65]. Glucose transport activity in the target tissue stimulated by FGF21 is accomplished mainly by the upregulation of GLUT1 transcription [8]. Previous research has shown that the increase in the mRNA levels of GK and GLUT1 and the decrease in mRNA levels of G6Pase and PEPCK can improve the condition of diabetes [66-68]. RT-PCR analysis revealed that PEG-FGF21 upregulated GK and GLUT1 mRNA expression and downregulated expression of G6Pase and PEPCK mRNA [63]. These results indicate that FGF21 stimulates the glucose uptake in HepG2 cells and maintains its long-lasting hypoglycemic activity by accelerating glycolysis, improving glucose uptake, and inhibiting gluconeogenesis (Fig. 2) [63].

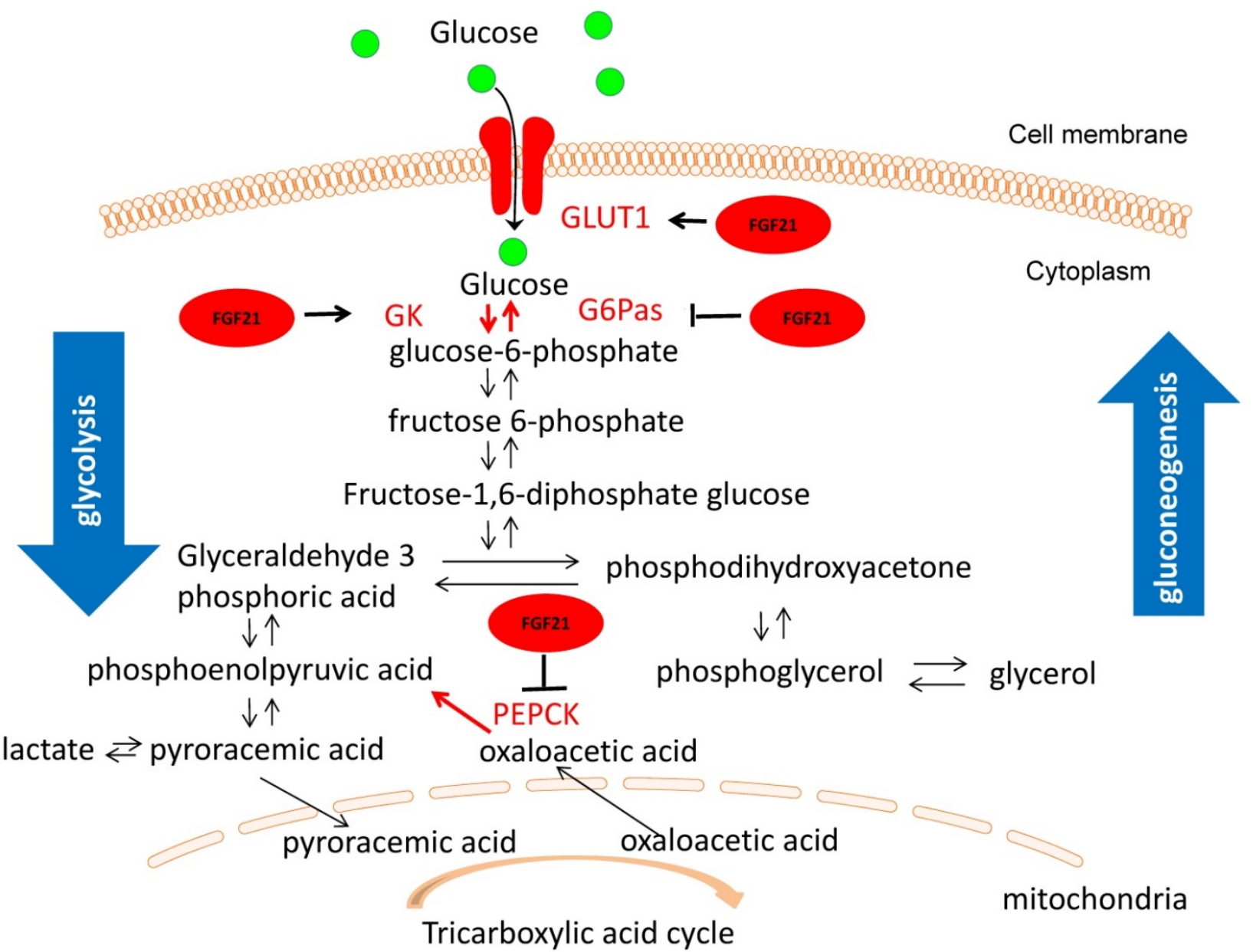

Figure 2. The underlying hypoglycemic mechanism of FGF21 in TID condition. FGF21 stimulates the glucose uptake in HepG2 cells and maintains its long-lasting hypoglycemic activity by upregulated expression of GK and GLUTI and downregulated expression of G6Pase and PEPCK, suggesting that FGF21 can accelerating glycolysis, improving glucose uptake, and inhibiting gluconeogenesis. It is known that aerobic respiration is divided into two stages: (I) In the cytoplasmic matrix, glucose decomposes into two molecules of pyroracemic acids; (2) Pyroracemic acid enters the mitochondrial matrix where it is used to produce ATP through the tricarboxylic acid cycle. Therefore, the hypoglycemic action of FGF21 occurs during the first phase of aerobic respiration. 
Besides HepG2 cells, other studies also proved the similar hypoglycemic effect of FGF21 by stimulating glucose uptake in 3T3-L1 adipocytes and skeletal muscle $[24,69,59]$.

\section{FGF21 prevents complications in TID}

FGF21 protects the myocardium from damage caused by TID

FGF21 deficiency has been reported to aggravate heart damage caused by severe cardiac lipid accumulation [70]. CD36 is a key lipid transporter that mediates cardiac fatty acid transport and utilization [71]. In the case of diabetes, elevated cardiac CD36 expression mediates over-uptake of fatty acids, leading to heart lipid accumulation [72]. Yan et al. found that cardiac CD36 expression is further upregulated in T1D and FGF21-KO mice, resulting in largely increased cardiac lipid accumulation due to upregulation of CD36-mediated accumulation of cardiac fatty acids [70]. RT-PCR analysis of heart tissues of T1D mice showed that the cardiac expression of FGFR1c and $\beta$-klotho was increased in the mice treated with fenofibrate (FF) a PPARa agonist, whereas their expression was significantly reduced in the T1D group and unchanged in the T1D / FF group [10]. It is known that FGF21 was first identified as one of the downstream PPARa genes in a mouse model that plays an important role in hepatic lipid homeostasis [73]. Therefore, we found that FF treatment upregulated cardiac FGF21 expression in T1D mouse cardiomyocytes and decreased the lipid-induced cardiac lipotoxicity [10]. In our other study, we found that the inhibition of ERK1/2 abolished the protective effect of FGF21 on palmitate-induced cardiomyocyte apoptosis and T1D-induced cardiac damage [74].

\section{FGF21 protects vessels from TID}

FGFR1c and $\beta$-klotho are highly expressed in the aorta [28], indicating that aortic and arterial vessels are also potential target tissues for FGF21. Circulating FGF21 level is positively correlated with coronary heart disease [75], and patients with T2D have a higher risk of cardiovascular events [76], suggesting a possible compensatory response. Therefore, FGF21 may serve as a biomarker for predicting subclinical atherosclerosis and cardiovascular events [77]. However, the studies of elevated circulating FGF21 levels are confined to obesity, dyslipidemia, and T2D $[39,78]$, and FGF21 is used only to predict these diseases. The direct protective effect of FGF21 on diabetic complications remains to be studied.

There is evidence that FGF21 reduces several risk factors for atherosclerosis and suppresses some of the key mechanisms involved in the pathogenesis of atherosclerosis [31, 79-82]. Endothelial dysfunction is considered the initiating factor for macrovascular disease and microangiopathy in T1D and T2D, which triggers diabetic vascular diseases [83]. Chronic inflammation and oxidative stress play an important role in the development and progression of a variety of chronic vascular pathologies, including endothelial remodeling and apoptotic cell death under diabetic conditions [84]. FGF21 has been reported to function in endothelial cells as anti-oxidative stress [80,82] and anti-apoptotic death [85], thereby hindering the development of atherosclerosis.

Clinical studies have shown that elevated serum FGF21 is closely associated with hypertension [86-88]. Zhu et al. revealed that FGF21 improves blood pressure in a fructose-induced hypertension model [89]. In addition, Zhang et al. found that elevated blood pressure in T1D mice can be prevented by supplementing FGF21 [74]. Therefore, FGF21-mediated antihypertensive effects also exert additional beneficial influence on diabetic-induced vascular lesions.

\section{FGF21 protects the kidney from T1D}

Diabetic kidney disease (DKD) starts with an early renal response to acute pathogenic stress in diabetes [90]. Lipid toxicity is considered to be a major cause of diabetic kidney damage and dysfunction in these early stages [91, 92]. Zhang et al. found that FGF21 plays a crucial role in the renal protection against lipid toxicity by preventing renal cell apoptosis and dysfunction [11]. Furthermore, FGF21 significantly prevented renal lipid accumulation and the subsequent inflammation, as well as oxidative damage and fibrosis [11].

Diabetes-induced renal oxidative stress, inflammation, apoptosis, and lipid and collagen accumulation were also found to be significantly attenuated by FF in a T1D mouse model [93]. FF significantly increased the expression of $f g f 21$ in the kidney, but the renal improvement by FF that was observed in wild-type T1D mice, was eliminated in FGF21-KO diabetic mice, and thus the key protective role of FGF21 in the kidneys from T1D was confirmed [93].

\section{FGF21 restores brown fat in T1D individuals}

Numerous studies have shown that FGF21 regulates glucose metabolism, the production and breakdown of adipose tissue, and lipid metabolism in white adipose tissue (WAT) by mediating the related gene expression $[17,59,60]$. It is well-known that uncoupling protein 1 (UCP1) is a typical protein in brown adipose tissue (BAT), to mediate uncoupling respiration and thermogenesis. Studies have 
demonstrated that in response to FGF21, UCP1 can be induced in WAT [94]. This phenomenon has been called "browning" of WAT cells. Therefore, FGF21 is able to use this mechanism to regulate thermogenesis [94]. In T1D, WAT is almost non-existent (Fig. 1F) and the reduction of blood glucose by FGF21 is the mechanism of restoring the function of BAT (Fig. 1G) [9].

BAT is an important tissue response to FGF21 $[95,96]$. In T1D, in the absence of insulin, BAT compromises its metabolic capacity and causes metabolic abnormalities [97]. Long-term administration of the FGF21 analogue (LY2405319) reduced blood glucose level while improving BAT glucose uptake (Fig. 1E) [9]. Moreover, the long-term administration of LY2405319 improved BAT morphology and gene expression profiling, and promoted the recovery of mitochondrial integrity and the establishment of lipid stores [9]. This is consistent with Adams's report that the transplantation of BAT into STZ-treated mice improves blood glucose level [95].

\section{Protective effects of FGF21 against T1D in other organs}

Jiang et al. found that $f g f 21$ gene deletion significantly increased not only spontaneously apoptotic cell death, but also T1D-induced apoptotic cell death in the testis, shown by the increased TUNEL positive cells, Bax/Bcl2 expression ratio and apoptosis-inducing factor (AIF) expression. Supplementation of exogenous FGF21 to these FGF21-KO mice significantly revised these enhanced effects, including T1D-induced TUNEL positive cells, increased $\mathrm{Bax} / \mathrm{Bcl} 2$ expression ratio and AIF expression along with oxidative damage. Therefore, this study indicates that $f g f 21$ gene may involve in maintaining normal spermatogenesis and also protect the germ cells from T1D-induced apoptotic cell death probably via the prevention of diabetes-induced oxidative damage [12].

FGF21 was found to be not expressed in the brain [28], however, if it is able to diffuse into the human cerebrospinal fluid [98] and into the hypothalamus of fasting mice [20] through the blood-brain barrier and further activates ERK1/2 phosphorylation in the brain $[98,99]$. The evidence that intracerebroventricular administration of exogenous FGF21 also increases energy expenditure and improves insulin sensitivity in obese rats [100], also suggests that FGF21 function directly in the brain. Diabetic neuropathy is another common complication of T1D, but no study has been done yet on neurodegeneration in T1D; therefore, the protective effect of FGF21 on T1D neurological complications remains to be completed.

\section{Mechanisms by which FGF21 protects T1D-induced complications}

\section{FGF21 reduces blood glucose and lipids in TID}

FGF21 maintains its long-lasting hypoglycemic activity by accelerating glycolysis, improving glucose uptake, and inhibiting gluconeogenesis [63]. Wente et al. reported that FGF21 improved pancreatic $\beta$-cell function and survival in an in vitro model [30]. They used rat islets and INS-1E cells, to show that pre-treatment of these cells with FGF21 could reduce the glucose-, lipid- and cytokine-induced apoptosis and maintain the function of these cells [30]. In contrast, in the study by Kim et al, FGF21 analogue treatment did not show increase in the blood insulin level in STZ-induced T1D mice, but remained significantly decreasing blood glucose levels [9]. Therefore, only based on these two studies, we can not make conclusion whether FGF21 can really reduce glucolipotoxicity- and inflammatory cytokine-caused pancreatic $\beta$-cell death and preserve the function of pancreatic $\beta$-cells under T1D conditions. The reasons include (1) whether the in vitro finding [30] can really represent the in vivo conditions remains examined; (2) the in vivo finding of no increase in blood insulin level by FGF21 analogue [9] is not direct evidence for the status of pancreatic $\beta$ cells. Therefore, we have to directly examine the pancreatic $\beta$-cell status for the T1D mice with and without FGF21 or its analogue treatment. In addition, FGF21 increases hepatic fatty acids utilization [73, 101] and is involved in the stimulation of $\beta$-oxidation of fatty acids [102].

FGF21 reduces lipid deposition and inhibits apoptosis, oxidative stress, and inflammation in organs under T1D conditions

Inhibition of lipid deposition by FGF21 has been reported by Yan et al [70]. In their examination, they discovered that $f g f 21$ gene deletion leads to predisposition to diabetic cardiomyopathy in STZ-induced T1D mice, which is mainly attributed to an increase in cardiac lipid accumulation that is upregulated by CD36-mediated accumulation of cardiac fatty acids [70]. In the study of Zhang et al., FF was found to increase Sirt1-mediated autophagy by upregulating cardiac expression of FGF21, thereby reducing lipid deposition in the heart of T1D mice [10]. The study of Zhang et al. confirmed that the protective effect of FGF21 against diabetic nephropathy is through the significant inhibition of the lipid accumulation in the kidney by exogenous FGF21 [11]. 
FGF21 reduces diabetes-induced apoptosis, thereby protecting from T1D complications. Inhibition of ERK1/2, p38 mitogen-activated protein kinase (MAPK) or adenosine monophosphate-activated protein kinase (AMPK) was found to eliminate the FGF21-mediated cardio-protection of palmitateinduced apoptosis in vitro, and the inhibition of ERK1/2 abrogated the protective effect of apoptosis of FGF21 in T1D induced cardiomyopathy [77]. Jiang et al. found that the deletion of $f g f 21$ gene enhanced T1D-induced testicular cell apoptosis, and the T1D-induced testicular cell apoptosis was significantly inhibited by exogenous FGF21 supplementation [12].

FGF21 may exert protective effects against atherosclerosis [83, 85] and diabetic nephropathy [1] through its antioxidant and/or anti-inflammatory properties. One possible cause of increased aortic disease in FGF21-KO diabetic mice is the endothelial nitric oxide synthase (eNOS) dysfunction. Deletion of eNOS genes increases leukocyte-endothelium interactions [103]. An earlier in vitro study [82] showed impaired eNOS phosphorylation at Ser-1177 and Ser-633 in HUVECs cells under diabetic conditions, which was reverted by FGF21 administration in an AMP-activated protein kinase-dependent manner. In one study, the eNOS phosphorylation of Ser-1177 in FGF21-KO T1D mice was more downregulated than WT diabetic mice, suggesting that FGF21 deficiency may aggravate aortic damage by eNOS activation damage [104].

Reportedly, FGF21 protects the heart from ischemia-induced oxidative damage primarily through its interaction with FGFR1 and $\beta$-Klotho receptors that activate the phosphoinositide 3-kinase (PI3K) / Akt-dependent cells survival pathway [105]. Oxidative stress and inflammation in the kidneys caused by T1D are also accompanied by a marked decrease of phosphorylation of PI3K, Akt, and glycogen synthase kinase-3 $\beta$ (GSK-3 $\beta$ ), and reduction of the nuclear factor-erythroid 2 (NF-E2)-related factor 2 (Nrf2) [93]. All these adverse effects were ameliorated by increased FGF21 expression induced by FF in WT T1D mice, but not in FGF21-KO T1D mice, confirming the pivotal protective role of FGF21 in T1D nephropathy [93]. However, some studies have shown that Nrf2 has an inhibitory effect on the induction of FGF21 [106]. Another study reported that Nrf2 has positive effect on FGF21 expression [107], while other studies also showed the induction of Nrf2 by FGF21 $[108,109]$. These findings suggest a complex relationship between FGF21 and Nrf2, which needs further systemic investigation in the future.

In addition, the inflammatory mediators in the blood can be downregulated by FGF21, and was found to be upregulated after $f g f 21$ gene was knock-down [81, 84, 85]. The mechanisms by which FGF21 control circulating inflammatory cytokines remain unclear.

In summary, based on the available research, we can conclude that the mechanisms by which FGF21 protects T1D-induced complications are multifaceted and complicated, as illustrated in Fig. 3.

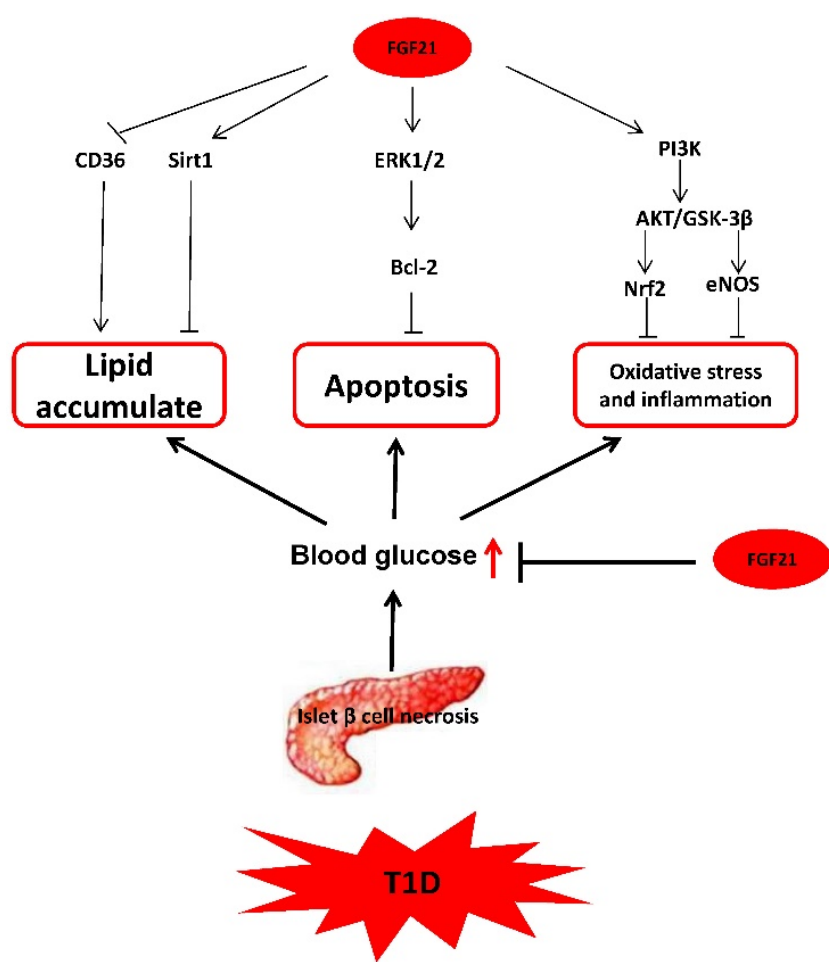

Figure 3. The mechanism of FGF21 protects TID-induced complications. FGF21 hypoglycemic activity by accelerating glycolysis, improving glucose uptake, and inhibiting gluconeogenesis reduces blood glucose in TID. FGF21 reduces lipid deposition and inhibits apoptosis, oxidative stress, and inflammation in organs under TID conditions to preventing TID complications.

\section{Effects of certain hormones on FGF21 expression}

There was a study using T1D mouse model, showing the significant decrease of plasma free fatty acids (FFA) with supplemented FGF21 [2]. Both in vitro and in vivo investigations indicate that the production of FGF21 is regulated by FFA in PPARa dependent manner [110]. However, the positive correlation between FFA concentrations and FGF21 production may be observed only at certain dose FFA levels (i.e: there is a threshold for FFA to stimulate FGF21 expression), whereas changes below the threshold may not have impact on FGF21 expression [110]. In addition to the regulation of FGF21 by FFA, systemic hormones can also modulate FGF21 production. 
The effect of insulin on FGF21 expression has been attracting broad research attention. Mraz et al. reported that effects of insulin on systemic level of FGF21 varied between obesity and lean individuals. They observed that FGF21 levels in lean patients did not change during hyperinsulinemic-euglycemic clamp test, whereas insulin-induced increases in FGF21 were found in obese patients [36]. Another study with healthy subjects also showed that hyper-physiological levels of insulin increase circulating FGF21 levels [110]. However, an increase of FGF21 level during hypoinsulinemia was detected in T1D patients, whereas no increase of FGF21 level by insulin under physiological conditions was detected [111]. It is noteworthy that the participants in one of the above studies were obese patients with impaired glucose tolerance [36], whereas the individuals in the T1D study were lean patients [111]. Therefore, the effect of insulin on FGF21 level may depend on body weight.

Glucagon was also found to affect FGF21 expression and elevated glucagon but low insulin levels during fasting contributed to the maintenance of normal blood glucose levels [49, 112]. Arafat et al. reported that glucagon increased the circulating FGF21 level in humans and rodents independently of endogenous insulin levels [113].

FGF21 plasma concentration is also affected by other hormones, such as the growth hormone $(\mathrm{GH})$, which can induce hepatic FGF21 production [114, 115], which is probably because GH-induced lipolytic release of FFA stimulates the hepatic FGF21 expression by activating the transcription factor PPARa [116].

\section{Conclusions and perspectives}

By reviewing previous studies, we conclude that FGF21 expression is regulated by several well-recognized antidiabetic drugs, such as metformin, glucagon-like peptide-1 (GLP-1) analogs, sirtuin1 activator, and PPAR agonists [56]. Although these antidiabetic drugs are used to improve the condition of T2D patients, an increasing body of studies on FGF21 in T1D animals also suggests that sirtuin1 activator and PPAR agonists may be considered drugs that prevent T1D complications too via induction of FGF21 [10].

In T1D mouse model, diabetes-induced oxidative stress and inflammation in kidneys were significantly attenuated by FF treatment along with increase in FGF21 expression and enhancing renal Nrf2 function [93]. In addition, a previous study found Nrf2-mediated upregulation of FGF21 in the liver, but not in other tissues, including WAT, BAT, and islets [107]. These results suggest that Nrf2 may positively regulate FGF21 in stressed mouse livers [107]. The main source of circulating FGF21 under normal physiological conditions is the liver [53]. Based on this fact, we assume whether a drug not only activates liver Nrf2 but also can increase the secretion of liver FGF21 into the circulation in T1D, so the Nrf2 and FGF21 have the synergic functions against oxidative stress and inflammation.

The native FGF21 protein exhibits poor pharmacokinetic characteristics with a short half-life $(0.5-2 \mathrm{~h})$ [7, 8, 59] and is prone to proteolytic degradation in vitro and in vivo. The small-sized FGF21 proteins (approximately $22 \mathrm{kDa}$ ) are easily eliminated by glomerular filtration in the kidneys [116], and therefore engineering methods have been developed to prolong the half-life and improve the stability, solubility, or potency of FGF21, and analogs, such as FGF21 (LY2405319) [63] and PEG-FGF21 [9] have been created and used. Several such modified FGF21 agents have been explored too [56].

Among the FGF21 analogues currently under investigation, LY2405319 [117] and PF-05231023 (also known as CVX-343) [118] have completed phase I clinical trials in T2D patients. Both LY2405319 and PF-05231023 can reduce total cholesterol and LDL in T2D patients and increase HDL. However, the study of LY2405319 and PF-05231023 in humans found that the hypoglycemic effect was weaker than in animal models of diabetes [9,119]. Bristol-Myers Squibb Company announced at the 2017 International Conference on Liver Disease that Phase II clinical trial of FGF21 analogue (BMS-986036) treatment for non-alcoholic fatty liver disease (NAFLD) can significantly reduce liver lipid content [120]. However, there was no any clinical trial using these FGF21 analogues for T1D patients.

FGF21 may also be a potential biomarker for the early diagnosis of certain metabolic diseases. This critical metabolic regulator governs the glucose and lipid metabolism and plays an important role in the treatment of metabolic diseases, such as T2D and obesity. In T1D, FGF21 also reduces blood glucose levels and prevents diabetic complications. However, the studies of FGF21 in T1D are extremely limited. Although FGF21 was detected in exocrine pancreas $[28,29]$, whether pancreatic $\beta$ cells express and secrete FGF21, thereby contributes to the reduced plasmaFGF21 levels caused by $\beta$ cell loss in T1D needs further substantiation. In addition, there are still some potential pitfalls of using transgenic animals in studies pertaining FGF21 and T1D. For instance, Yan et al. found that FGF21-KO had compensatory up-regulation of FGFR1 $m R N A$ expression in the heart under basal condition [70]. Since FGFR1 not only binds to FGF21 but also binds to FGF1, 2, 4, this 
compensatory effect maybe exert certain biological functions, resulting in misleading outcomes [121]. At the same time, the compensatory expression of FGFR1 increases the function of binding to exogenous FGF21, thereby amplifying the effect of FGF21 treatment. These deficiencies indicate that in the future there is still need for more FGF21 studies in T1D animal models. More investigations on T1D need to be conducted as well as human studies of FGF21 as the huge potential of FGF21 in the treatment of diabetes has been becoming increasingly evident.

\section{Acknowledgements}

This research was supported in part by grants from NSFC (81770374, to J.S.) and the American Diabetes Association (1-15-IBA-018; 1-18-IBS-082, to L.C.).

\section{Contributions of the Authors}

J.Z., J.S., and L.C. originally designed the project. J.Z. wrote the manuscript draft under L.C's guidance. L.C. was responsible for scientific review and manuscript editing. W.W., K.W. and X.L., searched the literature and revised the manuscript. All authors approved the final version of the manuscript.

\section{Competing Interests}

The authors have declared that no competing interest exists.

\section{References}

1. Nokoff NJ, Rewers M, Cree Green M. The interplay of autoimmunity and insulin resistance in type 1 diabetes. Discovery medicine. 2012; 13: 115-22.

2. Andersen B, Omar BA, Rakipovski G, Raun K, Ahren B. Fibroblast growth factor 21 prevents glycemic deterioration in insulin deficient mouse models of diabetes. European journal of pharmacology. 2015; 764: 189-94.

3. DeVries JH, Bain SC, Rodbard HW, Seufert J, D'Alessio D, Thomsen AB, et al. Sequential intensification of metformin treatment in type 2 diabetes with liraglutide followed by randomized addition of basal insulin prompted by A1C targets. Diabetes care. 2012; 35: 1446-54.

4. Kim HW, Lee JE, Cha JJ, Hyun YY, Kim JE, Lee MH, et al. Fibroblast growth factor 21 improves insulin resistance and ameliorates renal injury in $\mathrm{db} / \mathrm{db}$ mice. Endocrinology. 2013; 154: 3366-76.

5. Laeger T, Baumeier C, Wilhelmi I, Wurfel J, Kamitz A, Schurmann A. FGF21 improves glucose homeostasis in an obese diabetes-prone mouse model independent of body fat changes. Diabetologia. 2017; 60: 2274-84.

6. Wang Q, Yuan J, Yu Z, Lin L, Jiang Y, Cao Z, et al. FGF21 Attenuates High-Fat Diet-Induced Cognitive Impairment via Metabolic Regulation and Anti-inflammation of Obese Mice. Molecular neurobiology. 2017.

7. Xu J, Stanislaus S, Chinookoswong N, Lau YY, Hager T, Patel J, et al. Acute glucose-lowering and insulin-sensitizing action of FGF21 in insulin-resistant mouse models--association with liver and adipose tissue effects. American journal of physiology Endocrinology and metabolism. 2009; 297: E1105-14.

8. Kharitonenkov A, Wroblewski VJ, Koester A, Chen YF, Clutinger CK, Tigno $\mathrm{XT}$, et al. The metabolic state of diabetic monkeys is regulated by fibroblast growth factor-21. Endocrinology. 2007; 148: 774-81.

9. Kim JH, Bae KH, Choi YK, Go Y, Choe M, Jeon YH, et al. Fibroblast growth factor 21 analogue LY2405319 lowers blood glucose in streptozotocin-induced insulin-deficient diabetic mice by restoring brown adipose tissue function. Diabetes, obesity \& metabolism. 2015; 17: 161-9.

10. Zhang J, Cheng Y, Gu J, Wang S, Zhou S, Wang Y, et al. Fenofibrate increases cardiac autophagy via FGF21/SIRT1 and prevents fibrosis and inflammation in the hearts of Type 1 diabetic mice. Clinical science. 2016; 130: 625-41.

11. Zhang C, Shao M, Yang H, Chen L, Yu L, Cong W, et al. Attenuation of hyperlipidemia- and diabetes-induced early-stage apoptosis and late-stage renal dysfunction via administration of fibroblast growth factor-21 is associated with suppression of renal inflammation. PloS one. 2013; 8: e82275.
12. Jiang $X$, Zhang $C$, Xin $Y$, Huang $Z$, Tan $Y$, Huang $Y$, et al. Protective effect of FGF21 on type 1 diabetes-induced testicular apoptotic cell death probably via both mitochondrial- and endoplasmic reticulum stress-dependent pathways in the mouse model. Toxicology letters. 2013; 219: 65-76.

13. Fukumoto S. Actions and mode of actions of FGF19 subfamily members. Endocrine journal. 2008; 55: 23-31.

14. Zhang J, Li Y. Fibroblast growth factor 21, the endocrine FGF pathway and novel treatments for metabolic syndrome. Drug discovery today. 2014; 19 : 579-89.

15. Itoh N. Hormone-like (endocrine) Fgfs: their evolutionary history and roles in development, metabolism, and disease. Cell and tissue research. 2010; 342: $1-11$.

16. Goetz R, Beenken A, Ibrahimi OA, Kalinina J, Olsen SK, Eliseenkova AV, et al. Molecular insights into the klotho-dependent, endocrine mode of action of fibroblast growth factor 19 subfamily members. Molecular and cellular biology. 2007; 27: 3417-28.

17. Kurosu H, Choi M, Ogawa Y, Dickson AS, Goetz R, Eliseenkova AV, et al. Tissue-specific expression of betaKlotho and fibroblast growth factor (FGF) receptor isoforms determines metabolic activity of FGF19 and FGF21. The Journal of biological chemistry. 2007; 282: 26687-95.

18. Fukumoto $\mathrm{S}$, Yamashita T, FGF23 is a hormone-regulating phosphate metabolism--unique biological characteristics of FGF23. Bone. 2007; 40: 1190-5.

19. Turner N, Grose R. Fibroblast growth factor signalling: from development to cancer. Nature reviews Cancer. 2010; 10: 116-29.

20. Yang C, Jin C, Li X, Wang F, McKeehan WL, Luo Y. Differential specificity of endocrine FGF19 and FGF21 to FGFR1 and FGFR4 in complex with KLB. PloS one. 2012; 7: e33870.

21. Suzuki M, Uehara Y, Motomura-Matsuzaka K, Oki J, Koyama Y, Kimura M, et al. betaKlotho is required for fibroblast growth factor (FGF) 21 signaling through FGF receptor (FGFR) 1c and FGFR3c. Molecular endocrinology (Baltimore, Md). 2008; 22: 1006-14.

22. Kharitonenkov A, Dunbar JD, Bina HA, Bright S, Moyers JS, Zhang C, et al. FGF-21/FGF-21 receptor interaction and activation is determined by betaKlotho. Journal of cellular physiology. 2008; 215: 1-7.

23. Yie J, Hecht R, Patel J, Stevens J, Wang W, Hawkins N, et al. FGF21 N- and C-termini play different roles in receptor interaction and activation. FEBS letters. 2009; 583: 19-24

24. Ogawa Y, Kurosu H, Yamamoto M, Nandi A, Rosenblatt KP, Goetz R, et al. BetaKlotho is required for metabolic activity of fibroblast growth factor 21 . Proceedings of the National Academy of Sciences of the United States of America. 2007; 104: 7432-7.

25. Ding X, Boney-Montoya J, Owen BM, Bookout AL, Coate KC, Mangelsdorf DJ, et al. betaKlotho is required for fibroblast growth factor 21 effects on growth and metabolism. Cell metabolism. 2012; 16: 387-93.

26. Adams AC, Cheng CC, Coskun T, Kharitonenkov A. FGF21 requires betaklotho to act in vivo . PloS one. 2012; 7: e49977.

27. Ito S, Kinoshita S, Shiraishi N, Nakagawa S, Sekine S, Fujimori T, et al. Molecular cloning and expression analyses of mouse betaklotho, which encodes a novel Klotho family protein. Mechanisms of development. 2000; 98: 115-9.

28. Fon Tacer K, Bookout AL, Ding X, Kurosu H, John GB, Wang L, et al. Research resource: Comprehensive expression atlas of the fibroblast growth factor system in adult mouse. Molecular endocrinology (Baltimore, Md). 2010; 24: 2050-64.

29. Johnson CL, Weston JY, Chadi SA, Fazio EN, Huff MW, Kharitonenkov A, et al. Fibroblast growth factor 21 reduces the severity of cerulein-induced pancreatitis in mice. Gastroenterology. 2009; 137: 1795-804.

30. Wente W, Efanov AM, Brenner M, Kharitonenkov A, Koster A, Sandusky GE, et al. Fibroblast growth factor-21 improves pancreatic beta-cell function and survival by activation of extracellular signal-regulated kinase $1 / 2$ and Akt signaling pathways. Diabetes. 2006; 55: 2470-8.

31. Lin Z, Tian H, Lam KS, Lin S, Hoo RC, Konishi M, et al. Adiponectin mediates the metabolic effects of FGF21 on glucose homeostasis and insulin sensitivity in mice. Cell metabolism. 2013; 17: 779-89.

32. Holland WL, Adams AC, Brozinick JT, Bui HH, Miyauchi Y, Kusminski CM, et al. An FGF21-adiponectin-ceramide axis controls energy expenditure and insulin action in mice. Cell metabolism. 2013; 17: 790-7.

33. Maratos-Flier E. Fatty liver and FGF21 physiology. Experimental cell research. 2017; 360: 2-5.

34. Vandanmagsar B, Warfel JD, Wicks SE, Ghosh S, Salbaum JM, Burk D, et al. Impaired Mitochondrial Fat Oxidation Induces FGF21 in Muscle. Cell reports. 2016; 15: 1686-99.

35. Suomalainen A. Fibroblast growth factor 21: a novel biomarker for human muscle-manifesting mitochondrial disorders. Expert opinion on medical diagnostics. 2013; 7: 313-7.

36. Mraz M, Bartlova M, Lacinova Z, Michalsky D, Kasalicky M, Haluzikova D, et al. Serum concentrations and tissue expression of a novel endocrine regulator fibroblast growth factor- 21 in patients with type 2 diabetes and obesity. Clinical endocrinology. 2009; 71:369-75.

37. Chavez AO, Molina-Carrion M, Abdul-Ghani MA, Folli F, Defronzo RA, Tripathy D. Circulating fibroblast growth factor- 21 is elevated in impaired glucose tolerance and type 2 diabetes and correlates with muscle and hepatic insulin resistance. Diabetes care. 2009; 32: 1542-6.

38. Mashili FL, Austin RL, Deshmukh AS, Fritz T, Caidahl K, Bergdahl K, et al. Direct effects of FGF21 on glucose uptake in human skeletal muscle: 
implications for type 2 diabetes and obesity. Diabetes/metabolism research and reviews. 2011; 27: 286-97.

39. Chen C, Cheung BM, Tso AW, Wang Y, Law LS, Ong KL, et al. High plasma level of fibroblast growth factor 21 is an Independent predictor of type 2 diabetes: a 5.4-year population-based prospective study in Chinese subjects. Diabetes care. 2011; 34: 2113-5.

40. Fisher FM, Chui PC, Antonellis PJ, Bina HA, Kharitonenkov A, Flier IS, et al. Obesity is a fibroblast growth factor 21 (FGF21)-resistant state. Diabetes. 2010; 59: 2781-9.

41. Zhang X, Yeung DC, Karpisek M, Stejskal D, Zhou ZG, Liu F, et al. Serum FGF21 levels are increased in obesity and are independently associated with the metabolic syndrome in humans. Diabetes. 2008; 57: 1246-53.

42. So WY, Cheng Q, Chen L, Evans-Molina C, Xu A, Lam KS, et al. High glucose represses beta-klotho expression and impairs fibroblast growth factor 21 action in mouse pancreatic islets: involvement of peroxisome proliferator-activated receptor gamma signaling. Diabetes. 2013; 62: 3751-9.

43. Hale C, Chen MM, Stanislaus S, Chinookoswong N, Hager T, Wang M, et al. Lack of overt FGF21 resistance in two mouse models of obesity and insulin resistance. Endocrinology. 2012; 153: 69-80.

44. Reinehr T, Woelfle J, Wunsch R, Roth CL. Fibroblast growth factor 21 (FGF-21) and its relation to obesity, metabolic syndrome, and nonalcoholic fatty liver in children: a longitudinal analysis. The Journal of clinical endocrinology and metabolism. 2012; 97: 2143-50.

45. Donepudi AC, Boehme S, Li F, Chiang JY. G-protein-coupled bile acid receptor plays a key role in bile acid metabolism and fasting-induced hepatic steatosis in mice. Hepatology (Baltimore, Md). 2017; 65: 813-27.

46. Xiao Y, Xu A, Law LS, Chen C, Li H, Li X, et al. Distinct changes in serum fibroblast growth factor 21 levels in different subtypes of diabetes. The Journal of clinical endocrinology and metabolism. 2012; 97: E54-8.

47. Zibar K, Blaslov K, Bulum T, Cuca JK, Smircic-Duvnjak L. Basal and postprandial change in serum fibroblast growth factor-21 concentration in type 1 diabetic mellitus and in healthy controls. Endocrine. 2015; 48: 848-55.

48. Lin Z, Gong Q, Wu C, Yu J, Lu T, Pan X, et al. Dynamic change of serum FGF21 levels in response to glucose challenge in human. The Journal of clinical endocrinology and metabolism. 2012; 97: E1224-8.

49. Uebanso T, Taketani Y, Yamamoto H, Amo K, Ominami H, Arai H, et al. Paradoxical regulation of human FGF21 by both fasting and feeding signals: is FGF21 a nutritional adaptation factor? PloS one. 2011; 6: e22976.

50. Yang M, Dong J, Liu H, Li L, Yang G. Effects of short-term continuous subcutaneous insulin infusion on fasting plasma fibroblast growth factor-21 levels in patients with newly diagnosed type 2 diabetes mellitus. PloS one. 2011; 6: e26359.

51. Bisgaard A, Sorensen K, Johannsen TH, Helge JW, Andersson AM, Juul A. Significant gender difference in serum levels of fibroblast growth factor 21 in Danish children and adolescents. International journal of pediatric endocrinology. 2014; 2014: 7 .

52. Markan KR, Naber MC, Ameka MK, Anderegg MD, Mangelsdorf DJ, Kliewer SA, et al. Circulating FGF21 is liver derived and enhances glucose uptake during refeeding and overfeeding. Diabetes. 2014; 63: 4057-63.

53. Muise ES, Azzolina B, Kuo DW, El-Sherbeini M, Tan Y, Yuan X, et al. Adipose fibroblast growth factor 21 is up-regulated by peroxisome proliferator-activated receptor gamma and altered metabolic states. Molecular pharmacology. 2008; 74: 403-12.

54. Dushay J, Chui PC, Gopalakrishnan GS, Varela-Rey M, Crawley M, Fisher FM, et al. Increased fibroblast growth factor 21 in obesity and nonalcoholic fatty liver disease. Gastroenterology. 2010; 139: 456-63.

55. Yilmaz Y, Eren F, Yonal O, Kurt R, Aktas B, Celikel CA, et al. Increased serum FGF21 levels in patients with nonalcoholic fatty liver disease. European journal of clinical investigation. 2010; 40: 887-92.

56. So WY, Leung PS. Fibroblast Growth Factor 21 As an Emerging Therapeutic Target for Type 2 Diabetes Mellitus. Medicinal research reviews. 2016; 36: 672-704.

57. Uonaga T, Toyoda K, Okitsu T, Zhuang X, Yamane S, Uemoto S, et al. FGF-21 enhances islet engraftment in mouse syngeneic islet transplantation model. Islets. 2010; 2: 247-51.

58. Huang $\mathrm{X}, \mathrm{Yu} \mathrm{C}$, Jin C, Yang C, Xie R, Cao D, et al. Forced expression of hepatocyte-specific fibroblast growth factor 21 delays initiation of chemically induced hepatocarcinogenesis. Molecular carcinogenesis. 2006; 45: 934-42.

59. Kharitonenkov A, Shiyanova TL, Koester A, Ford AM, Micanovic R, Galbreath EJ, et al. FGF-21 as a novel metabolic regulator. The Journal of clinical investigation. 2005; 115: 1627-35.

60. Coskun T, Bina HA, Schneider MA, Dunbar JD, Hu CC, Chen Y, et al Fibroblast growth factor 21 corrects obesity in mice. Endocrinology. 2008; 149: 6018-27.

61. Ye X, Qi J, Sun G, Ren G, Zhu S, Wu Y, et al. Enhancement of the pharmacological efficacy of FGF-21 by genetic modification and PEGylation. Current pharmaceutical biotechnology. 2013; 14: 1287-98.

62. Huang Z, Wang H, Lu M, Sun C, Wu X, Tan Y, et al. A better anti-diabetic recombinant human fibroblast growth factor 21 (rhFGF21) modified with polyethylene glycol. PloS one. 2011; 6: e20669.

63. Xu P, Ye X, Zhang Y, Yuan Q, Liu M, Wu Q, et al. Long-acting hypoglycemic effects of PEGylated FGF21 and insulin glargine in mice with type 1 diabetes. Journal of diabetes and its complications. 2015; 29: 5-12.

64. Terauchi Y, Sakura H, Yasuda K, Iwamoto K, Takahashi N, Ito K, et al. Pancreatic beta-cell-specific targeted disruption of glucokinase gene. Diabetes mellitus due to defective insulin secretion to glucose. The Journal of biological chemistry. 1995; 270: 30253-6.

65. Sato T, Toyoshima A, Hiraki T, Ohta Y, Katayama K, Arai T, et al. Effects of metformin on plasma concentrations of glucose and mannose, G6Pase and PEPCK activity, and mRNA expression in the liver and kidney of chickens. British poultry science. 2011; 52: 273-7.

66. Agius L. Targeting hepatic glucokinase in type 2 diabetes: weighing the benefits and risks. Diabetes. 2009; 58: 18-20.

67. Haber BA, Chin S, Chuang E, Buikhuisen W, Naji A, Taub R. High levels of glucose-6-phosphatase gene and protein expression reflect an adaptive response in proliferating liver and diabetes. The Journal of clinical investigation. 1995; 95: 832-41.

68. Lu L, Seidel CP, Iwase T, Stevens RK, Gong YY, Wang X, et al. Suppression of GLUT1; a new strategy to prevent diabetic complications. Journal of cellular physiology. 2013; 228: 251-7.

69. Izumiya Y, Bina HA, Ouchi N, Akasaki Y, Kharitonenkov A, Walsh K. FGF21 is an Akt-regulated myokine. FEBS letters. 2008; 582: 3805-10.

70. Yan X, Chen J, Zhang C, Zhou S, Zhang Z, Chen J, et al. FGF21 deletion exacerbates diabetic cardiomyopathy by aggravating cardiac lipid accumulation. Journal of cellular and molecular medicine. 2015; 19: 1557-68.

71. Koonen DP, Glatz JF, Bonen A, Luiken JJ. Long-chain fatty acid uptake and FAT/CD36 translocation in heart and skeletal muscle. Biochimica et biophysica acta. 2005; 1736: 163-80.

72. Greenwalt DE, Scheck SH, Rhinehart-Jones T. Heart CD36 expression is increased in murine models of diabetes and in mice fed a high fat diet. The Journal of clinical investigation. 1995; 96: 1382-8.

73. Badman MK, Pissios P, Kennedy AR, Koukos G, Flier IS, Maratos-Flier E. Hepatic fibroblast growth factor 21 is regulated by PPARalpha and is a key mediator of hepatic lipid metabolism in ketotic states. Cell metabolism. 2007; 5: 426-37.

74. Zhang C, Huang Z, Gu J, Yan X, Lu X, Zhou S, et al. Fibroblast growth factor 21 protects the heart from apoptosis in a diabetic mouse model via extracellular signal-regulated kinase 1/2-dependent signalling pathway. Diabetologia. 2015; 58: 1937-48.

75. Shen Y, Ma X, Zhou J, Pan X, Hao Y, Zhou M, et al. Additive relationship between serum fibroblast growth factor 21 level and coronary artery disease. Cardiovascular diabetology. 2013; 12: 124.

76. Ong KL, Januszewski AS, O'Connell R, Jenkins AJ, Xu A, Sullivan DR, et al. The relationship of fibroblast growth factor 21 with cardiovascular outcome events in the Fenofibrate Intervention and Event Lowering in Diabetes study. Diabetologia. 2015; 58: 464-73.

77. Kokkinos J, Tang S, Rye KA, Ong KL. The role of fibroblast growth factor 21 in atherosclerosis. Atherosclerosis. 2017; 257: 259-65.

78. Woo YC, Xu A, Wang Y, Lam KS. Fibroblast growth factor 21 as an emerging metabolic regulator: clinical perspectives. Clinical endocrinology. 2013; 78: 489-96.

79. Lin Z, Pan X, Wu F, Ye D, Zhang Y, Wang Y, et al. Fibroblast growth factor 21 prevents atherosclerosis by suppression of hepatic sterol regulatory element-binding protein-2 and induction of adiponectin in mice. Circulation. 2015; 131: 1861-71.

80. Zhu W, Wang C, Liu L, Li Y, Li X, Cai J, et al. Effects of fibroblast growth factor 21 on cell damage in vitro and atherosclerosis in vivo. Canadian journal of physiology and pharmacology. 2014; 92: 927-35.

81. Zhu S, Ma L, Wu Y, Ye X, Zhang T, Zhang Q, et al. FGF21 treatment ameliorates alcoholic fatty liver through activation of AMPK-SIRT1 pathway. Acta biochimica et biophysica Sinica. 2014; 46: 1041-8.

82. Wang XM, Song SS, Xiao H, Gao P, Li XJ, Si LY. Fibroblast growth factor 21 protects against high glucose induced cellular damage and dysfunction of endothelial nitric-oxide synthase in endothelial cells. Cellular physiology and biochemistry: international journal of experimental cellular physiology, biochemistry, and pharmacology. 2014; 34: 658-71.

83. Coccheri S. Approaches to prevention of cardiovascular complications and events in diabetes mellitus. Drugs. 2007; 67: 997-1026.

84. Insull W, Jr. The pathology of atherosclerosis: plaque development and plaque responses to medical treatment. The American journal of medicine. 2009; 122: S3-S14.

85. Lu Y, Liu JH, Zhang LK, Du J, Zeng XJ, Hao G, et al. Fibroblast growth factor 21 as a possible endogenous factor inhibits apoptosis in cardiac endothelial cells. Chinese medical journal. 2010; 123: 3417-21.

86. Semba RD, Crasto C, Strait J, Sun K, Schaumberg DA, Ferrucci L. Elevated serum fibroblast growth factor 21 is associated with hypertension in community-dwelling adults. Journal of human hypertension. 2013; 27: 397-9.

87. Lin Z, Wu Z, Yin X, Liu Y, Yan X, Lin S, et al. Serum levels of FGF-21 are increased in coronary heart disease patients and are independently associated with adverse lipid profile. PloS one. 2010; 5: e15534

88. Chow WS, $\mathrm{Xu}$ A, Woo $\mathrm{YC}$, Tso AW, Cheung SC, Fong $\mathrm{CH}$, et al. Serum fibroblast growth factor-21 levels are associated with carotid atherosclerosis independent of established cardiovascular risk factors. Arteriosclerosis, thrombosis, and vascular biology. 2013; 33: 2454-9.

89. Zhu SL, Ren GP, Zhang ZY, Wang WF, Ye XL, Han MM, et al. [Therapeutic effect of fibroblast growth factor 21 on hypertension induced by insulin resistance]. Yao xue xue bao = Acta pharmaceutica Sinica. 2013; 48: 1409-14.

90. Wu J, Guan TJ, Zheng S, Grosjean F, Liu W, Xiong H, et al. Inhibition of inflammation by pentosan polysulfate impedes the development and 
progression of severe diabetic nephropathy in aging C57B6 mice. Laboratory investigation; a journal of technical methods and pathology. 2011; 91: 1459-71.

91. Kim MY, Lim JH, Youn HH, Hong YA, Yang KS, Park HS, et al. Resveratrol prevents renal lipotoxicity and inhibits mesangial cell glucotoxicity in a manner dependent on the AMPK-SIRT1-PGC1alpha axis in $\mathrm{db} / \mathrm{db}$ mice. Diabetologia. 2013; 56: 204-17.

92. Shapiro H, Theilla M, Attal-Singer J, Singer P. Effects of polyunsaturated fatty acid consumption in diabetic nephropathy. Nature reviews Nephrology. 2011; 7: 110-21.

93. Cheng Y, Zhang J, Guo W, Li F, Sun W, Chen J, et al. Up-regulation of Nrf2 is involved in FGF21-mediated fenofibrate protection against type 1 diabetic nephropathy. Free radical biology \& medicine. 2016; 93: 94-109.

94. Fisher FM, Kleiner S, Douris N, Fox EC, Mepani RJ, Verdeguer F, et al. FGF21 regulates PGC-1alpha and browning of white adipose tissues in adaptive thermogenesis. Genes \& development. 2012; 26: 271-81.

95. Adams AC, Yang C, Coskun T, Cheng CC, Gimeno RE, Luo Y, et al. The breadth of FGF21's metabolic actions are governed by FGFR1 in adipose tissue. Molecular metabolism. 2012; 2: 31-7.

96. Ohta H, Itoh N. Roles of FGFs as Adipokines in Adipose Tissue Development, Remodeling, and Metabolism. Frontiers in endocrinology. 2014; 5: 18.

97. Seydoux J, Chinet A, Schneider-Picard G, Bas S, Imesch E, Assimacopoulos-Jeannet $\mathrm{F}$, et al. Brown adipose tissue metabolism in streptozotocin-diabetic rats. Endocrinology. 1983; 113: 604-10.

98. Tan BK, Hallschmid M, Adya R, Kern W, Lehnert H, Randeva HS. Fibroblast growth factor 21 (FGF21) in human cerebrospinal fluid: relationship with plasma FGF21 and body adiposity. Diabetes. 2011; 60: 2758-62.

99. Liang Q, Zhong L, Zhang J, Wang Y, Bornstein SR, Triggle CR, et al. FGF21 maintains glucose homeostasis by mediating the cross talk between liver and brain during prolonged fasting. Diabetes. 2014; 63: 4064-75.

100. Sarruf DA, Thaler JP, Morton GJ, German J, Fischer JD, Ogimoto K, et al. Fibroblast growth factor 21 action in the brain increases energy expenditure and insulin sensitivity in obese rats. Diabetes. 2010; 59: 1817-24.

101. Fisher FM, Chui PC, Nasser IA, Popov Y, Cunniff JC, Lundasen T, et al. Fibroblast growth factor 21 limits lipotoxicity by promoting hepatic fatty acid activation in mice on methionine and choline-deficient diets. Gastroenterology. 2014; 147(e6): 1073-83.

102. Planavila A, Redondo I, Hondares E, Vinciguerra M, Munts C, Iglesias R, et al. Fibroblast growth factor 21 protects against cardiac hypertrophy in mice. Nature communications. 2013; 4: 2019

103. Lefer DJ, Jones SP, Girod WG, Baines A, Grisham MB, Cockrell AS, et al. Leukocyte-endothelial cell interactions in nitric oxide synthase-deficient mice. The American journal of physiology. 1999; 276: H1943-50.

104. Yan X, Chen J, Zhang C, Zeng J, Zhou S, Zhang Z, et al. Fibroblast growth factor 21 deletion aggravates diabetes-induced pathogenic changes in the aorta in type 1 diabetic mice. Cardiovascular diabetology. 2015; 14: 77.

105. Liu SQ, Roberts D, Kharitonenkov A, Zhang B, Hanson SM, Li YC, et al. Endocrine protection of ischemic myocardium by FGF21 from the liver and adipose tissue. Scientific reports. 2013; 3: 2767 .

106. Chartoumpekis DV, Ziros PG, Psyrogiannis AI, Papavassiliou AG, Kyriazopoulou VE, Sykiotis GP, et al. Nrf2 represses FGF21 during long-term high-fat diet-induced obesity in mice. Diabetes. 2011; 60: 2465-73.

107. Furusawa Y, Uruno A, Yagishita Y, Higashi C, Yamamoto M. Nrf2 induces fibroblast growth factor 21 in diabetic mice. Genes to cells: devoted to molecular \& cellular mechanisms. 2014; 19: 864-78.

108. Ye D, Wang Y, Li H, Jia W, Man K, Lo CM, et al. Fibroblast growth factor 21 protects against acetaminophen-induced hepatotoxicity by potentiating $\begin{array}{lll}\text { peroxisome proliferator-activated receptor coactivator } & \text { cor }\end{array}$ protein-1alpha-mediated antioxidant capacity in mice. Hepatology (Baltimore, Md). 2014; 60: 977-89.

109. Yu Y, Bai F, Liu Y, Yang Y, Yuan Q, Zou D, et al. Fibroblast growth factor (FGF21) protects mouse liver against D-galactose-induced oxidative stress and apoptosis via activating Nrf2 and PI3K/Akt pathways. Molecular and cellular biochemistry. 2015; 403: 287-99.

110. Mai K, Andres J, Biedasek K, Weicht J, Bobbert T, Sabath M, et al. Free fatty acids link metabolism and regulation of the insulin-sensitizing fibroblast growth factor-21. Diabetes. 2009; 58: 1532-8.

111. Mai K, Bobbert T, Groth C, Assmann A, Meinus S, Kraatz J, et al. Physiological modulation of circulating FGF21: relevance of free fatty acids and insulin. American journal of physiology Endocrinology and metabolism. 2010; 299: E126-30.

112. Berglund ED, Kang L, Lee-Young RS, Hasenour CM, Lustig DG, Lynes SE, et al. Glucagon and lipid interactions in the regulation of hepatic AMPK signaling and expression of PPARalpha and FGF21 transcripts in vivo . American journal of physiology Endocrinology and metabolism. 2010; 299: E607-14.

113. Arafat AM, Kaczmarek P, Skrzypski M, Pruszynska-Oszmalek E, Kolodziejski P, Szczepankiewicz D, et al. Glucagon increases circulating fibroblast growth factor 21 independently of endogenous insulin levels: a novel mechanism of glucagon-stimulated lipolysis? Diabetologia. 2013; 56: 588-97.

114. Chen W, Hoo RL, Konishi M, Itoh N, Lee PC, Ye HY, et al. Growth hormone induces hepatic production of fibroblast growth factor 21 through a mechanism dependent on lipolysis in adipocytes. The Journal of biological chemistry. 2011; 286: 34559-66.

115. Braun LR, Feldpausch MN, Czerwonka N, Torriani M, Grinspoon SK, Stanley TL. Fibroblast growth factor 21 decreases after liver fat reduction via growth hormone augmentation. Growth hormone \& IGF research: official journal of the Growth Hormone Research Society and the International IGF Research Society. 2017; 37: 1-6.

116. Maack T, Johnson V, Kau ST, Figueiredo J, Sigulem D. Renal filtration, transport, and metabolism of low-molecular-weight proteins: A review. Kidney International. 1979; 16: 251-70.

117. Gaich G, Chien JY, Fu H, Glass LC, Deeg MA, Holland WL, et al. The effects of LY2405319, an FGF21 analog, in obese human subjects with type 2 diabetes. Cell Metab. 2013; 18: 333-340.

118. Dong JQ, Rossulek M, Somayaji VR, Baltrukonis D, Liang Y, Hudson K, et al. Pharmacokinetics and pharmacodynamics of PF-05231023, a novel long-acting FGF21 mimetic, in a first-in-human study. Br J Clin Pharmacol. 2015; 80: 1051-1063.

119. Huang J, Ishino $T$, Chen G, Rolzin $P$, Osothprarop TF, Retting $K$, et al. Development of a novel long-acting antidiabetic FGF21 mimetic by targeted conjugation to a scaffold antibody. J Pharmacol Exp Ther. 2013; 346: 270-280.

120. Arun S, Edgar DC, Brent N, Rohit L, Stephen H, Manal FA, et al. BMS-986036 (pegylated FGF21) in patients with non-alcoholic steatohepatitis: A phase 2 study. The International Liver Conference, European Association for the Study of the Liver (EASL)Amsterdam. The Netherlands. 2017; Publication number: LBO-01.

121. Katoh M. Therapeutics Targeting FGF Signaling Network in Human Diseases. Trends Pharmacol Sci. 2016; 37: 1081-1096. 